\title{
The effect of particle size and solvent type on the gallic acid yield obtained from Labisia pumila by ultrasonic extraction
}

\author{
Afiqah Yeop ${ }^{1,3}$, Jessinta Sandanasamy ${ }^{1,3}$, Sook Fun Pang ${ }^{1,3}$, Sureena Abdullah ${ }^{1,3}$, Mashitah M. Yusoff ${ }^{2}$, and Jolius \\ Gimbun ${ }^{1,3 *}$ \\ ${ }^{1}$ Centre of Excellence for Advanced Research in Fluid Flow (CARIFF), Universiti Malaysia Pahang, Gambang 26300, Pahang, Malaysia \\ ${ }^{2}$ Faculty of Industrial Science and Technology, Universiti Malaysia Pahang, Gambang 26300, Pahang, Malaysia \\ ${ }^{3}$ Faculty of Chemical and Natural Resources Engineering, Universiti Malaysia Pahang, Gambang 26300, Pahang, Malaysia
}

\begin{abstract}
This paper presents the effect of particle size and solvent type on the gallic acid (GA) extraction yield obtained from Labisia pumila. The GA extraction from a grinded dried plant material $(66.66 \mu \mathrm{m}$ to $1055.18 \mu \mathrm{m})$ was performed using the sonicator probe. The GA quantification and identification was performed using a liquid chromatography with photodiode array detector. Exact match between the spectra obtained from the plant extract and external standard was found indicating a presence of GA. In addition, matching of residence time between the standard and plant extract are also observed. It was found that particle size significantly affects the yield of GA and the highest yield $(0.150 \mathrm{mg} \mathrm{GA} / \mathrm{g} \mathrm{DW})$ was obtained using the particle size around $125 \mu \mathrm{m}$. Solvent type does also plays an important role in GA extraction. The result shows that extraction using water as solvent yielded about $29 \%$ higher GA content $(0.126 \mathrm{mg} \mathrm{GA} / \mathrm{g}$ DW) than that of $10 \%$ ethanol $(0.098 \mathrm{mg} \mathrm{GA} / \mathrm{g} \mathrm{DW})$. The findings in this work may serve as a useful guide to select the particle size and solvent used to maximise GA extraction from $L$. pumila.
\end{abstract}

\section{Introduction}

Labisia pumila, (vernacular name: 'kacip fatimah') had been recognised in the Malaysian National Key Economic Areas (NKEA) to be developed as an herb for commercial purposes. It is an extensively consumed herb in Southest Asia regions. L. pumila traditionally used to induce and facilitate childbirth, as health supplement, as treatment for rheumatism, intestine infection, prostate cancer, dysentery, dysmenorrheal, flatulence and gonorrhea [1-3]. Previous scientific studies revealed that the extract of $L$. pumila enclosed many medically worthy bioactive compounds such as phenolics, flavonoids, vitamins and proteins that poses numerous biological effects (antibacterial, antioxidant, anticancer, antiobesity, cytotoxic) [4-8]. Many authors had recognized gallic acid as the core compound of L. pumila [5, 9-10]. Gallic acid is an organic phenolic acid that is commonly found in foods such as apples, tea leaves, blueberries, and walnuts. Recently, gallic acid derivatives considerably improve the assessment of mechanisms of action in human and murine cell lineages with promising antitumor activity [11]. Ishihara and Sakagami [12] had reported the cytotoxic activity of gallic acid against human leukemia (HK-63) cell lines whereas Saleem et al. [13] reported that gallic acid exhibits cytotoxic potential on HOS-1 cell lines. However, limited study is available concerning the effect of particle size and solvent on the gallic acid extraction from L. pumila.

Extraction of gallic acid from $L$. pumila is an important step before it can be developed further as supplement or functional foods. Many conventional methods (maceration, soxhlet and decoction) had been applied intensively by several researchers to extract the plant polyphenols [14-17]. Recent studies also focus on the modern method such as ultrasound assisted extraction (UAE). UAE was shown to be the most effective extraction method based on high yield, high selectivity and reduction in extraction time and solvent consumption. The UAE technique reduced the inner and external mass transfer limitation and hence increases the yield of extraction [18]. In addition, ultrasonic waves can break the cell membrane which enhances the inner mass transport. Thus UAE was employed in this work to extract gallic acid from L. pumila.

Besides the extraction technique, the particle size of plant also affects the extraction yield. The smaller the particle size of the material, the shorter the path of the solvent has to travel; which indirectly decreases the time for maximum phytochemical extraction [19]. Smaller particles also have a much larger surface area and hence providing a greater mass transfer rate. According to Fonseca et al. [20], grinding the material indirectly damages the plant cellular which leads to better extraction. For instance, Baldosano et al. [21] reported that finer particle produced higher yield of tannin, similar finding are also reported by Roriguez-Miranda et al. [22].

Water and other organic solvents (ethanol, acetonitrile, acetone, hexane and diethyl ether) are usually used for extraction of bioactive compounds [23]. The difference in polarities of the solvents may influence

Corresponding author: jolius@ump.edu.my

(C) The Authors, published by EDP Sciences. This is an open access article distributed under the terms of the Creative Commons Attribution License 4.0 (http://creativecommons.org/licenses/by/4.0/). 
the solubility of the chemical constituents and their extraction yield. According to Pang et al. [24], the yield of methoxylated and hydroxylated polyphenols is greatly affected by the solvent type used. They found that aqueous alcohol is the best solvent to simultaneously extract the methoxylated and hydroxylated polyphenols $[24,25]$. Recently, Sandanasamy et al. [26] reported that $10 \%$ ethanol yielded the highest yield of total phenolic and flavonoid extraction from $L$. pumila, however the effect of solvent on the yield specific polyphenol such as gallic acid is not available. Therefore, this work aims to elucidate the effect of particle size and solvent type on the gallic acid extraction from $L$. pumila using UAE method.

\section{Materials and methods}

\subsection{Chemicals and plant material}

Standard GA was obtained from Acros Organics, Fisher Scientific (Leicestershire, UK) whereas analysis grade ethanol was obtained from Merck (Darmstadt, Germany). HPLC grade trifluoroacetic acid (TFA) and acetonitrile was obtained from Fisher Scientific (Leicestershire, UK) and Merck (Darmstadt, Germany), respectively. $L$. pumila var. pumila was procured from a trader in Kuantan, Malaysia. The plant materials were washed with deionized water to remove impurities and were dried under open air. Subsequently, the material is ovendried at the temperature of $37^{\circ} \mathrm{C}$ until no significant change in weight. The dried plant was grounded into powder and were sieved with analytical sieve shaker (Retsch AS 200, Germany) into five groups of mesh $(\leq 125,>125-\leq 250,>250-\leq 500,>500-\leq 800$ and $>800$ $\mu \mathrm{m})$. The moisture content was determined using a moisture analyzer (AND MS-70, Japan). The powderized plant was preserved in an air-tight plastic at room temperature prior to extraction.

\subsection{Ultrasonic assisted extraction (UAE)}

Extracts were prepared according to different mesh using Qsonica Q700 (Newtown, USA) equipped with a standard probe. A volume of $100 \mathrm{~mL}$ of solvent (water and $10 \%$ ethanol) were added into weighted powder (dry weight) at the solid-to-solvent ratio of 0.05 . The mixture was then immediately sonicated at the amplitude of $90 \%$ for the extraction time of $10 \mathrm{~min}$. The supernatant was then separated by centrifugation (Eppendorf $5810 \mathrm{R}$, Hamburg, Germany) at $10000 \mathrm{rpm}$ for $10 \mathrm{~min}$ to obtain a clear solution. The extracts were then stored at $-80^{\circ} \mathrm{C}$ prior to GA quantification.

\subsection{Particle size distribution}

The particle size distribution of plant powder was measured using laser diffraction particle size analyzer (Malvern 2000 mastersizer, Malvern Instruments Co., Worcestershire, UK) equipped with an automated dry powder dispersion unit (Scirocco 2000). The distribution was characterized by the volume weighted mean. Prior to analysis of the distribution, the refractive index of the powder were determined by calibration curve at different concentration $(5,10,20,30,40$ and $50 \%)$ of powder in water suspension. The curve was extrapolated to $100 \%$ to obtain the refractive index value of the dry powder.

\subsection{Gallic acid quantification}

The quantification of GA was performed on Waters Acquity UPLC H-Class (Milford, USA) fitted with Purospher® STAR RP-18 Endcapped Hibar UHPLC column $(2 \mu \mathrm{m}, 100$ x $2.1 \mathrm{~mm})$ (Merck, Darmstadt, Germany). The UPLC system is equipped with photodiode array detector operated via Waters Empower 3 software. The operating conditions were at room temperature, with injection volume of $3 \mu \mathrm{L}$ and flowrate at $0.17 \mathrm{~mL} / \mathrm{min}$. The mobile phase consists of $0.1 \%$ TFA (solvent A) and $0.1 \%$ TFA in acetonitrile (solvent B). The performed elution scheme were: 0-2.0 min, 90\% A; 2-2.4 min, 90-88\% A; 2.4-3.1 min, 88\% A; 3.1-4.3 min, 88-85\% A; 4.3-5.5 min, 85\% A; 5.5-6.7 min, 85-80\% A; 6.7-7.5 min, 80\% A; 7.5-8.8 $\mathrm{min}, 80-75 \%$ A; 8.8-9.7 min, $75 \%$ A; 9.7-10.5 min, 75-70\% A; 10.5-11.5 min, $70 \% \mathrm{~A} ; 11.5-12 \mathrm{~min}, 70-5 \% \mathrm{~A}$; and finally washing the column with isocratic $5 \% \mathrm{~A}$; and reconditioning with 90\% A for $3 \mathrm{~min}$. The extract and standard were filtered with $0.22 \mu \mathrm{m}$ nylon membrane prior to injection. The peak of GA in comparison with the standard were detected at $280 \mathrm{~nm}$.

\subsection{Statistical analysis}

The influence of the different particle size was assessed via an analysis of mean and standard deviation using analysis tools in Microsoft Excel 2013.

\section{Results and discussion}

\subsection{Quantification of gallic acid in L. pumila}

The GA was identified by means of the retention time and UV spectra of the standard. The quantitative analysis performed by determining the concentration of the GA peak area in comparison with the results of a calibration series using standards obtained from Fisher Scientific. The seven point calibration curve in the concentration range of $0.001-0.5 \mathrm{mg} / \mathrm{mL}$ showed good linearity $\left(\mathrm{R}^{2}=\right.$ 0.9985) (Fig. 1). UV spectra of GA from L. pumila extracts were found to be in a good match with the standard compound (Fig. 2). Thus, this confirmed its presence in the extracts. Fig. 3 shows the UPLC overlay chromatogram profile of $L$. pumila extract and standard. The developed UPLC separation requires a run time of $23 \mathrm{~min}$ and GA were spotted at $2.255 \mathrm{~min}$. Therefore, this method is capable for an accurate qualitative and quantitative analysis of gallic acid from $L$. pumila extract. Thus similar method was used to quantify gallic acid from the extracts throughout this work. 


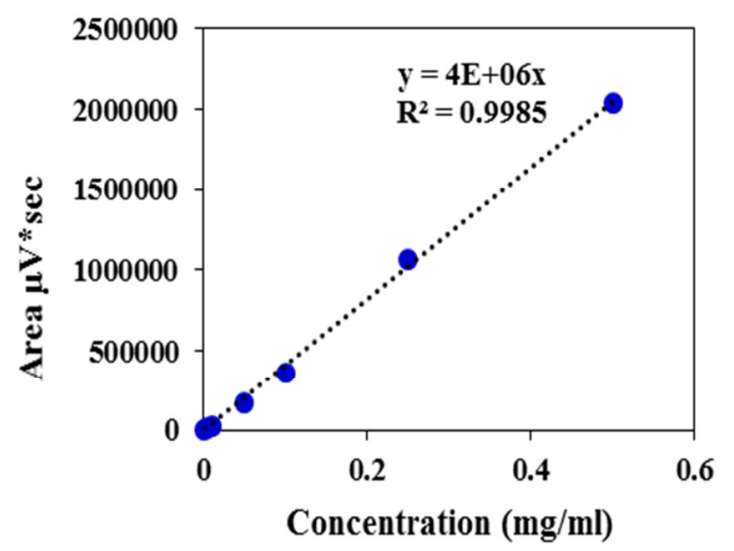

Fig. 1. Calibration curve of standard GA
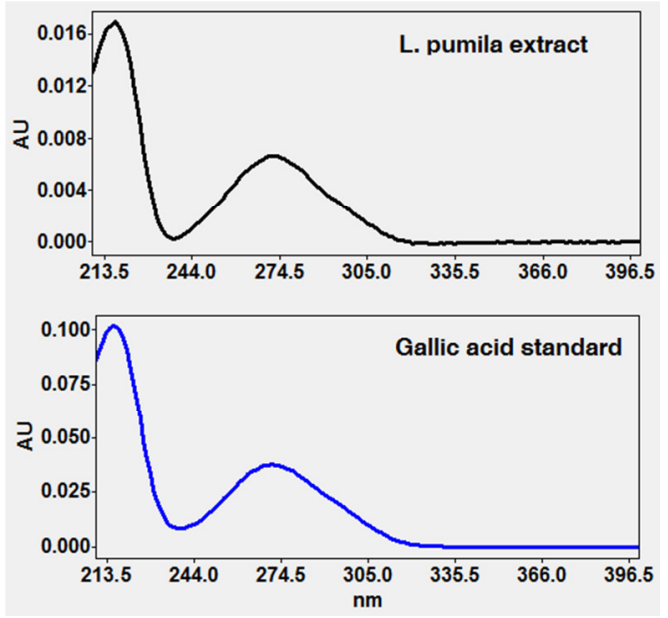

Fig. 2. Spectra of standard GA and L. pumila extract.

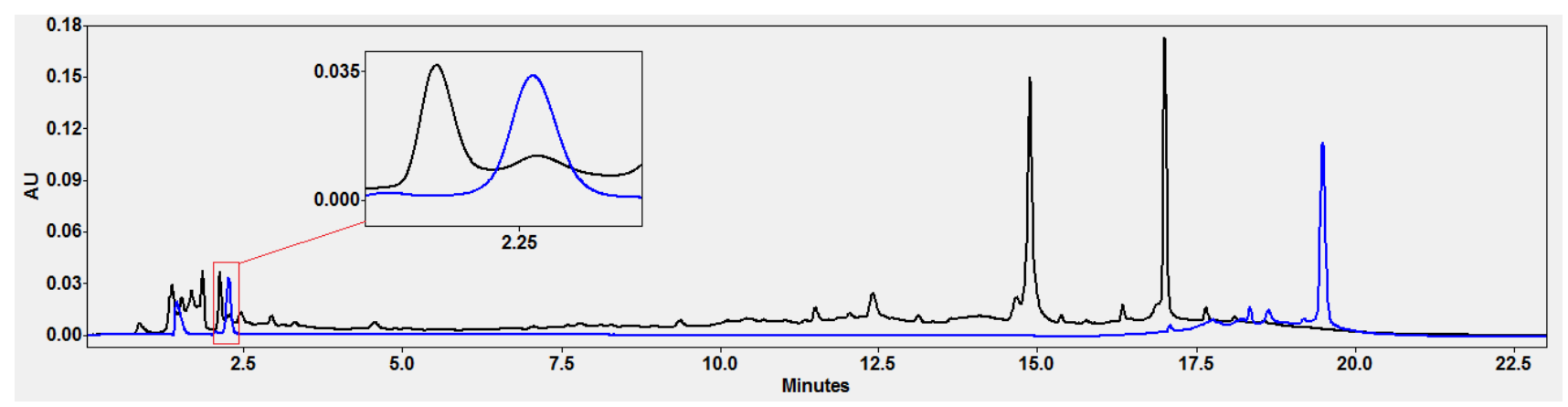

Fig. 3. UPLC overlay chromatogram of GA standard and L. pumila extract recorded at $280 \mathrm{~nm}$

\subsection{Effect of particle size on gallic acid recovery}

Grinding and classification according to the particle size were made before the extraction of GA was performed to increase surface area and hence the mass transfer efficiency. Furthermore, grinding breaks the plant cell wall, thus facilitating active compounds release to the extraction solvent and enhancing the yield.

The effect of particle size on the extraction yield during UAE was examined under conditions of similar extraction volume $(100 \mathrm{~mL})$, solid-to-solvent ratio (1:20), amplitude $(90 \%)$ and time (10 min). The $L$. pumila powders consisted of particles with the smallest diameter of $1.4 \mu \mathrm{m}$, while the largest size detected was $2000 \mu \mathrm{m}$ (Fig. 4). The particle size distribution curves (mesh size of $>125-\leq 250,>250-\leq 500,>500-\leq 800$ and $>800 \mu \mathrm{m})$ is a monomodal with a log normal type distribution. The particle obtained from mesh size of $\leq 125 \mu \mathrm{m}$ found to be slightly bimodal due to the fact that all particles smaller than $125 \mu \mathrm{m}$ falls under this size. It is possible that the grinded particles still have many finer particle classes, but it cannot be separated due to the limitation of the equipment. Nevertheless, fine particle $<125 \mu \mathrm{m}$ is not good for extraction as they tend to float. Hence, it is not important do further separate the particle smaller than $125 \mu \mathrm{m}$. The powders had average particle size of $66.66 \mu \mathrm{m}$ to $1055.18 \mu \mathrm{m}$ and surface weighted mean ranging from $31.24 \mu \mathrm{m}$ to $642.77 \mu \mathrm{m}$ (Table 1).

It was found that the recovery of GA from L. pumila is significantly affected by the particle size. The highest extraction yield of GA $(0.15 \mathrm{mg} \mathrm{GA} / \mathrm{g}$ DW $)$ was obtained using particle size of $>125-\leq 250 \mu \mathrm{m}$ (Fig. 5).
Particle size of $\leq 125 \mu \mathrm{m}$ is smaller than the one in the range of $>125-\leq 250 \mu \mathrm{m}$, in which supposed to give better yield of GA due to its higher surface area. However, the very small particles are more prone to float in the extraction solvent and therefore, the contact with the solvent is limited [27]. Therefore, the GA yield for particle $<125 \mu \mathrm{m}$ is lesser than that of $>125-\leq 250 \mu \mathrm{m}$.

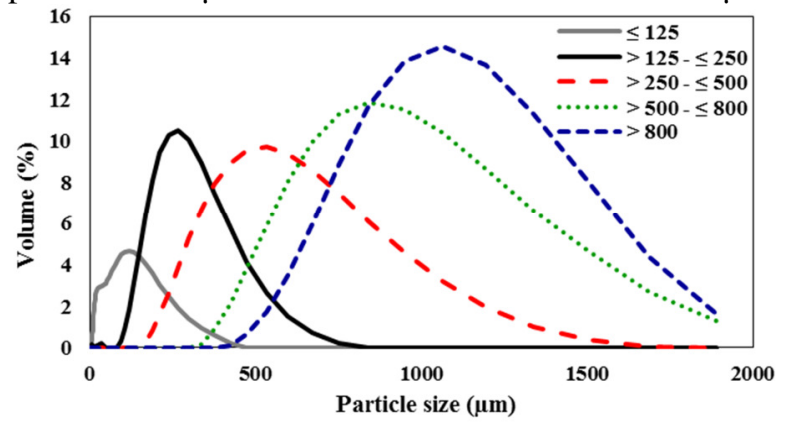

Fig. 4. Particle size distribution of L. pumila powder

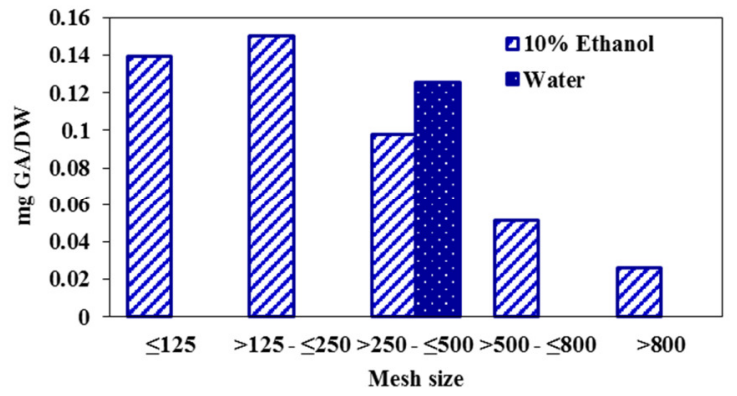

Fig. 5. Quantification of GA in different mesh size of L. pumila 
Table 1. Average particle size and surface weighted mean of L. pumila powders

\begin{tabular}{|l|l|l|}
\hline Mesh size range $(\mu \mathrm{m})$ & \multicolumn{1}{|c|}{$\mathrm{d}(0.5)(\mu \mathrm{m})$} & \multicolumn{1}{|c|}{$\mathrm{D}[3,2](\mu \mathrm{m})$} \\
\hline$\leq 125$ & $66.66 \pm 1.99$ & $31.24 \pm 0.36$ \\
\hline$>125-\leq 250$ & $252.15 \pm 5.57$ & $140.97 \pm 2.11$ \\
\hline$>250-\leq 500$ & $517.10 \pm 0.25$ & $453.46 \pm 20.48$ \\
\hline$>500-\leq 800$ & $858.15 \pm 10.29$ & $804.90 \pm 9.34$ \\
\hline$>800$ & $1055.18 \pm 34.18$ & $642.77 \pm 469.40$ \\
\hline
\end{tabular}

\subsection{Effect of type of solvent on gallic acid recovery}

Generally ethanol and water are mostly used in the extraction of bioactive compounds as they have been classified as GRAS (Generally Recognized as Safe) solvents [28]. The results showed that the extraction using water as solvent yielded about $29 \%$ higher GA content $(0.126 \mathrm{mg} \mathrm{GA} / \mathrm{g} \mathrm{DW})$ than that of $10 \%$ ethanol $(0.098 \mathrm{mg} \mathrm{GA} / \mathrm{g} \mathrm{DW})$ for particle size ranged from $>250$ $-\leq 500 \mu \mathrm{m}$. Solvent of different polarities have effect on the efficiency of extraction of polyphenolic from plants. In terms of polarity, water has higher polarity than that of $10 \%$ ethanol. In this case, GA which is classified as a polar phenolic compound [29] is more soluble in water i.e. solvent of higher polarity. Thus explaining why the GA yield is higher when water is used instead of aqueous ethanol. Paini et al. [30] explained that the higher vapour pressure and viscosity of ethanol with respect to water can decrease the force of the implosion of the cavitation bubbles. Consequently, the implosion cause less effective solid material disruption which is vital for gallic acid release from the plant material. Earlier, Paini et al. [30] also obtained lower total phenolic content from agri-food waste with high percentage of ethanol via UAE. Similarly, Fecka and Turek [31] also reported a higher yield of polyphenol with solvent containing higher water content from maceration of thyme and marjoram.

\section{Conclusion}

The UPLC separation method developed in this work for L. pumila extracts had successfully identified and confirmed the presence of GA by the means of spectral and residence time match. The recovery of GA generally increase as the particle size decreases, however the highest yield $(0.15 \mathrm{mg} \mathrm{GA} / \mathrm{g} \mathrm{DW})$ was obtained from particle size distribution in the range of $>125-\leq 250 \mu \mathrm{m}$. Water provide about $29 \%$ higher yield of GA than that of aqueous $10 \%$ ethanol via UAE extraction. The findings in this work may serve as a useful guide to maximise GA extraction from L. pumila.

We acknowledge funding from Ministry of Higher Education Malaysia FRGS/1/2016/TK02/UMP/02/4 (RDU160124) and Universiti Malaysia Pahang (PGRS 160301).

\section{References}

1. M.H. Ibrahim, H.Z.E. Jaafar, E. Karimi, A. Ghasemzadeh, Sci. World J. 2014, 1-13 (2014)
2. N. Jamaludin, R. Hasham, I. Ware, M.R. Sarmidi, R. Abd Aziz, J. Technol. 77, 61-66 (2015)

3. N. A. Kamarudin, M. Markom, J. Latip, Indian J. Sci. Technol. 9, 3-7 (2016)

4. Z. Ali, I. Khan, Phytochemistry 72, 2075-2080 (2011)

5. E. Karimi, H.Z.E. Jaafar, Molecules 16, 6791-6805 (2011)

6. L.S. Chua, N.A. Latiff, S.Y. Lee, C.T. Lee, M.R. Sarmidi, R.A. Aziz, Food Chem. 127, 1186-1192 (2011)

7. N.A. Al-Mekhlafi, K. Shaari, F. Abas, R. Kneer, E.J. Jeyaraj, J. Stanslas, N.H. Lajis, Phytochemistry 80, 42-49 (2012)

8. A. Pandey, S. Bani, P.L. Sangwan, Adv. Res. 2, 556-570 (2014)

9. A. Mohd Azrie, A. Luqman Chuah, K.Y. Pin, H.P. Ta. J. Chem. and Pharma. Res. 6, 172-332 (2014)

10. Mohd Abdah, Siti Nadiah, Sarmidi, Mohammad Roji, Yaakob, Harisun and I. Ware, J. Technol. 69, 65-68 (2014)

11. C. Locatelli, F.B. Filippin-Monteiro, T.B. Creczynski-Pasa, European J. Med. Chem. 60, 233239 (2013)

12. M. Ishihara, H. Sakagami, Anticancer Res. 23, 2549-2552 (2003)

13. A. Saleem, M. Husheem, P. Harkonen, K. Pihlaja, Ethnopharmacol. J. 81, 327-336 (2002)

14. Y. Pan, K.H. Tiong, B.A. Abd-Rashid, Z. Ismail, R. Ismail, J.W. Mak, C.E. Ong J. of Ethnopharmacol. 143, 586-591 (2012)

15. H.K. Choi, D.H. Kim, J.W. Kim, S. Ngadiran, M.R. Sarmidi, C.S. Park, Journal of Biosci. Bioeng. 109, 291-296 (2010)

16. A. Pandey, S. Bani, P. Sangwan, S. Koul. J. Ethnopharmacol. 132, 309-315 (2010)

17. A.H. Al-Adhroey, Z.M. Nor, H.M. Al-Mekhlafi, R. Mahmud J. Ethnopharmacol. 132, 362-364 (2010)

18. S.F. Pang, M. Yusoff, A. Luqman, C. J. Gimbun, Sci. Technol. Prog. 1, 10-13 (2015).

19. J. Shi, H. Nawaz, J. Pohorly, G. Mittal, Y. Kakuda, Y. Jiang, Food Rev. Int. 21, 139-166 (2005)

20. J.M. Fonseca, J.W. Rushing, R.L. Thomas, M.B. Riley, N.C. Rajapakse, J. Herbs Spices Med. Plants 12, 139-152 (2006)

21. H.Y. Baldosano, M.B.M.G. Castillo, C.D.H. Elloran, F.T. Bacani, DLSU Res. Cong. 3, 4-9 (2015)

22. J. Rodríguez-Miranda, B. Hernández-Santos, E. Herman-Lara, C.A. Gómez-Aldapa, H.S. Garcia, C.E. Martínez-Sánchez, CyTA J. Food 12, 9-15 (2014)

23. A. Dailey, Q.V. Vuong, Cogent Food Agri. 7, 1-10 (2015)

24. S. F. Pang, M. Z. Lau, M. M. Yusoff, J. Gimbun, Materials Science Forum, 890, 155-158 (2017)

25. S. F. Pang, M. M. Yusoff, J. Gimbun, Food Hydrocolloids, 890, 155-158 (2017).

26. J. Sandanasamy, M. M. Yusoff, J. Gimbun, Materials Science Forum, 890, 167-170 (2017).

27. C.L. Paiva, W.P. Evangelista, V.A.V. Queiroz, M.B.A. Gloria, Food Chem. 173, 224-230 (2015) 
28. Y.M. Monroy, R.A.F. Rodrigues, A. Sartoratto, F.A. Cabral, J. Supercrit. Fluids 116, 10-19 (2016)

29. D. Boskou, M. Tsimidou, G. Blekas, Polar Chemical Compounds in Olive Oil, Chemistry and Technology, (Champaign, Illinois: AOCS Press, 2006)

30. M. Paini, A.A. Casazza, B. Aliakbarian, P. Perego, A. Binello, G. Cravotto, Int. J. Food. Sci. Technol. 51, 349-358 (2016)

31. I. Fecka, S. Turek, Food Chem. 108, 1039-1053 (2008) 